\title{
Activation of signal transducer and activator of transcription 5 (STAT5) is linked to $\beta 1$-integrin protein abundance in unilaterally milked bovine mammary glands
}

\author{
R. Murney, ${ }^{*} \dagger^{1}$ K. Stelwagen, $\ddagger$ T. T. Wheeler, ${ }^{*}$ J. K. Margerison, $\dagger$ and K. Singh* \\ ${ }^{*}$ AgResearch Ltd., Ruakura Research Centre, P.B. 3123, Hamilton 3240, New Zealand \\ tInstitute of Agriculture and Environment, College of Sciences, Massey University, P.B. 11222, Palmerston North 4442, New Zealand \\ ¥SciLactis Ltd., Waikato Innovation Park, Hamilton 3240, New Zealand
}

\begin{abstract}
Prolactin $(\mathrm{PRL})$ is important in the regulation of milk synthesis in mammary epithelial cells (MEC). In cattle, circulating levels of PRL are not limiting, suggesting the possible involvement of other factors that may control the response to PRL at the cellular level. The effects of milking frequency (MF) on milk synthesis are controlled locally within mammary glands and involve PRL signaling. To further investigate this relationship between $\mathrm{MF}$ and $\mathrm{PRL}$ signaling, udder halves of 17 dairy cows were milked either 4 times a day $(4 \times)$ or once a day $(1 \times)$ for $14 \mathrm{~d}$ in early lactation. Mammary biopsies were obtained 3 to $5 \mathrm{~h}$ following milking from both udder halves of 10 cows, and changes in PRL and associated pathways were measured. The abundance of $S T A T 5 A$ mRNA was higher after $4 \times$ milking, whereas that of the PRL receptor $(P R L R)$ and STAT3 were lower relative to that after $1 \times$ milking. In $4 \times$ mammary tissues, the protein levels of STAT5, activated STAT5, and $\beta 1$-integrin were higher, whereas the those of the long isoform of PRL receptor and activated STAT3 were lower than $1 \times$ tissues. The activation of STAT5 correlated strongly with major milk protein mRNA abundance $(r=0.86$ to 0.94$)$ and $\beta 1$-integrin protein levels $(r=0.91)$. These results confirm that major milk protein gene expression is associated with STAT5 activation and suggests that the STAT5 and $\beta 1$-integrin signaling pathways are linked. Modulation of $\beta 1$-integrin abundance in response to changes in MF may be a mechanism that controls the MEC ability to respond to PRL and therefore its secretory activity.
\end{abstract}

Key words: milking frequency, mammary, milk synthesis, cell signaling

Received October 21, 2014.

Accepted January 12, 2015.

${ }^{1}$ Corresponding author: regan.murney@agresearch.co.nz

\section{INTRODUCTION}

In lactating mammary glands, prolactin (PRL) is important for the regulation of milk synthesis in mammary epithelial cells (MEC; Flint and Knight, 1997). The PRL signal is transmitted into the cell through its receptor (PRLR), which facilitates the activation of 2 closely related signaling proteins, signal transducer and activator of transcription (STAT) 5A and 5B. When activated, the STAT5 proteins form homodimers and are transported to the nucleus, where they activate expression of genes involved in milk synthesis. This relationship between PRL signaling and milk synthesis has been well established in rodent models (reviewed in Flint and Knight, 1997). Administration of bromocriptine, which blocks PRL release from the pituitary gland, inhibits further milk secretion in rodents (Shaar and Clemens, 1972; Knight et al., 1986); however, the relationship is unclear in cattle. During lactogenesis, in the period leading up to parturition, there is a surge in circulating PRL (Ingalls et al., 1973). Inhibition of this surge with bromocriptine can decrease subsequent milk yield (MY; Akers et al., 1981). However, once lactation has been established, blocking release of PRL with bromocriptine has little effect on MY (Smith et al., 1974). Nevertheless, recent studies have shown that another PRL release-blocking agent, quinagolide, applied over a longer period in mid-lactation does decrease MY (Lacasse et al., 2011), suggesting that PRL may have a galactopoietic effect under certain conditions.

Unilateral MF (UMF) models, where udder halves are milked independently at differing MF, have demonstrated that the effects on MY and MEC activity are predominantly controlled locally within the treated mammary gland (Stelwagen and Knight, 1997; Wall and McFadden, 2007; Murney et al., 2015). Dairy cows are commonly milked twice a day $(\mathbf{2} \times)$, but increasing $\mathrm{MF}$ to 4 times a day $(4 \times)$ can increase MY by up to $20 \%$ compared with $2 \times$ (Stelwagen, 2001). This response is immediate (Hillerton et al., 1990; Murney et al., 2015) and has been observed at most stages of 
lactation (reviewed in Erdman and Varner, 1995). Similarly, decreasing MF from $2 \times$ to once a day $(\mathbf{1} \times)$ has a negative effect on MY (Carruthers et al., 1993; Rémond et al., 1999).

The mechanisms underlying the MY response to MF are not well understood, but are most likely a function of secretory MEC number, activity, or both. In mammary glands during lactation, the number of MEC is controlled by the rates of proliferation and apoptosis (Capuco et al., 2001), which may be modulated by MF (Boutinaud et al., 2013; Murney et al., 2015). However, changes in cell number are thought to be incremental and occur over the course of days to weeks (Capuco et al., 2001) and are unlikely to account for the $60 \%$ shift in MY in response to differential MF that occurs within $2 \mathrm{~d}$ of commencement of treatment (Murney et al., 2015). Therefore, at least part of the response to MF may be through the modulation of the secretory activity of MEC. An increase in the mRNA abundance of both the long and short isoforms of the PRLR (Bernier-Dodier et al., 2010) occurs in response to increased MF. In addition, quinagolide treatment had more of an effect on the MY of udder halves milked $2 \times$ compared with $1 \times$ (Lacasse et al., 2011). These results suggest a possible link between MF and PRL signaling that is manifested through alteration of the sensitivity of MEC to circulating PRL.

Signaling from the extracellular matrix via integrins is necessary for appropriate MEC differentiation and milk synthesis (Sympson et al., 1994; Roskelley et al., 1995). It has been demonstrated in mouse knockout models that $\beta 1$-integrin is essential for mammary gland development and sustained STAT5 activation (Naylor et al., 2005; Akhtar and Streuli, 2006). In normal mammary glands of mice (McMahon et al., 2004) and cows (Singh et al., 2008), the level of $\beta 1$-integrin protein decreases during involution, which suggests that the abundance of this protein is modulated during physiological changes in mammary tissue function. Furthermore, in cow mammary glands, this decrease coincides with a decrease in STAT5 activation (Singh et al., 2009).

The ability of MEC to respond to PRL can be perturbed by the presence of antagonistic factors. In mammary glands, STAT3 activation is pro-apoptotic and can be induced by the leukemia inhibitory factor (LIF) pathway (Kritikou et al., 2003). Activation of STAT3 has been shown to occur during involution in both mouse and bovine mammary glands (Kritikou et al., 2003; Singh et al., 2009) and coincides with the inactivation of STAT5. Evidence from in vitro models suggests that the activation of STAT3 can inhibit activation of STAT5 and vice versa (Clarkson et al., 2006; Granillo et al., 2007), but whether this occurs in vivo is unclear.
In this study, a UMF model was used to investigate PRL signaling in mammary glands of dairy cows. We hypothesized that the MY response to increased MF is a result of an increase in MEC sensitivity to circulating PRL. If so, this could be manifested through changes in the abundance of constituents of the PRL signaling pathway or cross talk from other stimuli, such as extracellular matrix interactions via $\beta 1$-integrin or STAT3 activation. We therefore investigated changes in these signaling proteins, and their encoding mRNA, in response to altered MF.

\section{MATERIALS AND METHODS}

\section{Animals and Treatments}

All animal manipulations were conducted in compliance with the rules and guidelines of the Ruakura Animal Ethics Committee. Animal management and treatments have been described previously (Murney et al., 2015). Briefly, the udder halves of 17 cows were randomly assigned a MF of either $4 \times$ or $1 \times(4 \times$ in one udder half at $0500,1100,1700$, and $2300 \mathrm{~h}$, and $1 \times$ in the other udder half at $1100 \mathrm{~h}$ ) for $14 \mathrm{~d}$ from 5 \pm 2 DIM. The MY of $4 \times$ and $1 \times$ udder halves were $8.4 \pm 0.5 \mathrm{~kg} / \mathrm{d}$ and $8.5 \pm 0.5 \mathrm{~kg} / \mathrm{d}$, respectively, before commencement of the treatment, and were $15.0 \pm 0.7$ $\mathrm{kg} / \mathrm{d}$ and $7.5 \pm 0.3 \mathrm{~kg} / \mathrm{d}$ for $4 \times$ and $1 \times$ treatments, respectively, by the end of the 14-d period. Biopsies of mammary gland tissue were taken from both rear quarters of 10 cows 3 to $5 \mathrm{~h}$ after the $1100 \mathrm{~h}$ milking, as previously described (Farr et al., 1996). Briefly, this involved excision of approximately $0.5 \mathrm{~g}$ of alveolar tissue from a site distal to the cistern and major ducts using a modified purpose-built drill rotating stainless steel cannula. A portion of the mammary tissue was fixed overnight in $4 \%$ paraformaldehyde and processed into wax as described previously (Singh et al., 2005). The remainder was snap-frozen in liquid nitrogen for subsequent molecular analysis of mRNA and protein.

\section{RNA Isolation and Reverse Transcription}

Total RNA was isolated from $100 \mathrm{mg}$ of mammary tissue using Trizol reagent (Life Technologies, Grand Island, NY) according to the manufacturer's instructions and quantified using a Nanodrop 1000 spectrophotometer (Nanodrop, Wilmington, DE). The RNA integrity was measured on an Agilent 2100 Bioanalyser (Agilent, Santa Clara, CA) with an RNA integrity number $>5$ considered sufficient for real-time, reverse transcriptionPCR analysis. For cDNA synthesis, $1 \mu \mathrm{g}$ of total RNA was purified using RNAeasy columns (Qiagen, Valencia, CA), according to the supplied RNA clean-up protocol 
(Qiagen) and converted using the SuperScript III reverse transcription kit (Life Technologies) according to the manufacturer's instructions. The amount of cDNA equivalent to $5 \mathrm{ng}$ of starting total RNA was used as template for each real-time PCR reaction. Primer pairs for genes of interest and housekeeper genes are listed in Table 1. Primers for PRLR short and long isoforms, STAT5A, and STAT3 were designed using Primer3 (Untergasser et al., 2012). Primers have been reported previously for $\beta 1$-integrin (ITGB1) and focal adhesion kinase (FAK; Singh et al., 2005), $\alpha_{\mathrm{S1}^{-}} \mathrm{CN}(\boldsymbol{C S N 1} \boldsymbol{S} 1)$, $\alpha$-LA $(\boldsymbol{L} \boldsymbol{A} \boldsymbol{L} \boldsymbol{B} \boldsymbol{A})$, and $\beta$-LG $(\boldsymbol{L} \boldsymbol{G B}$; Murney et al., 2015), $\beta-C N$ ( $\boldsymbol{C S N 2}$ ) and ubiquitin B (UBB ; Singh et al., 2008), and $\beta 2$ microglobulin (B2 $\boldsymbol{M}$; Wall and McFadden, 2010). Real-time PCR was carried out on a Corbett Rotorgene 6000 (Qiagen) with SYBR ExTaq Mix (Takara Bio Inc., Shiga, Japan) with a 3-min denaturation, followed by 40 cycles of $95^{\circ} \mathrm{C}$ for $10 \mathrm{~s}$ and $60^{\circ} \mathrm{C}$ for $30 \mathrm{~s}$. Relative mRNA abundance for genes of interest were calculated in relation to the geometric mean of the mRNA abundance of 2 housekeeper genes ( $U B B$ and B2M) as previously described (Smith et al., 2010), with these modifications; threshold crossover values $\left(\mathrm{C}_{t}\right)$ were replaced with take-off values, and amplification efficiencies were calculated using the comparative quantification analysis tool of Rotogene 6000 series software 1.7 (Qiagen). The PCR products were verified by sequencing (Waikato DNA Sequencing Facility, Hamilton, New Zealand).

\section{Protein Extraction and Western Blotting}

Total protein was isolated from previously snapfrozen mammary biopsy samples by homogenization in a buffer containing $10 \mathrm{~m} M$ HEPES, $\mathrm{pH} 7.9$, $1.5 \mathrm{mM} \mathrm{MgCl}, 10 \mathrm{mM} \mathrm{KCl}$, and protease inhibitors as described previously (McMahon et al., 2004). Protein concentration was determined using the Bradford method (Bradford, 1976), and $20 \mu \mathrm{g}$ of total protein was separated on 10\% BisTris NuPAGE gels (Life Technologies) and transferred onto nitrocellulose membranes (Pall Corporation, East Hills, NY). Membranes were blocked in Tris-buffered saline (TBS) solution (0.05 $M$ Tris-HCl, $0.15 M$ NaCl, pH 7.6) containing $0.1 \%$ Tween 20 (TBST), $0.1 \%$ BSA, and $4 \%$ nonfat milk for $2 \mathrm{~h}$. After 3 washes in TBST-BSA, membranes were incubated for $2 \mathrm{~h}$ in TBST-BSA with antibodies targeting PRLR (long; 1:1,000, sc-30225, Santa Cruz Biotechnology, Santa Cruz, CA), PRLR (short; 1:2,000, C61-K5, kindly provided by A. J. Nixon, AgResearch Ltd., Hamilton, New Zealand), STAT5A/B (STAT5, 1:10,000, sc-835, Santa Cruz Biotechnology), Tyr 694-phosphorylated STAT5A/B (STAT5-P, 1:30,000; Wheeler et al., 2001), STAT3 (1:10,000, sc-482, Santa

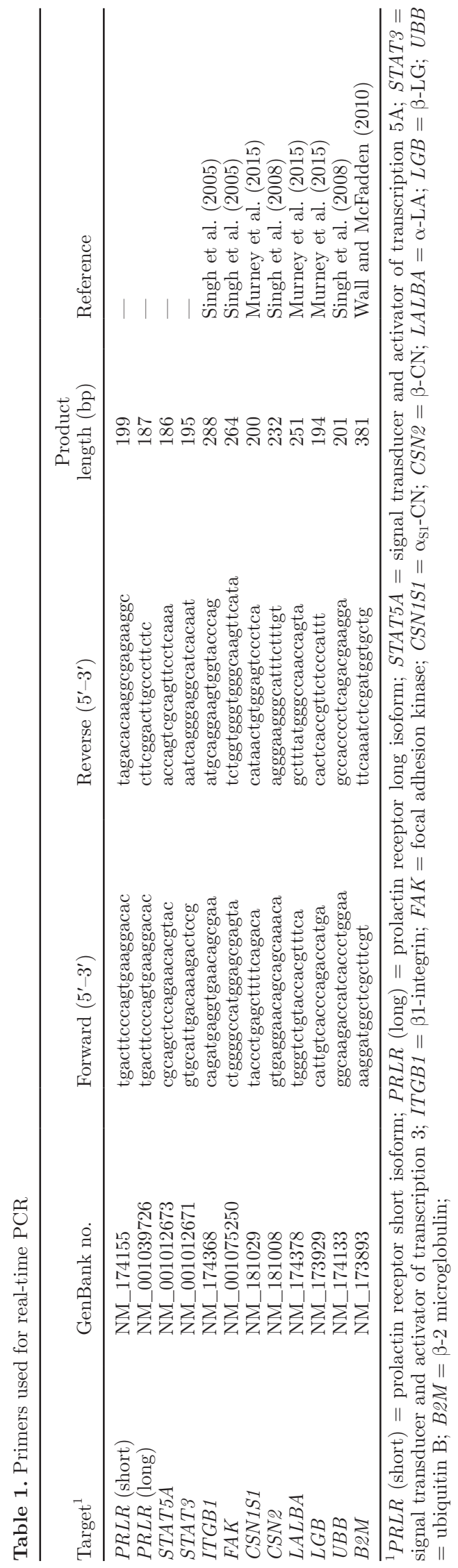

Journal of Dairy Science Vol. 98 No. 5, 2015 
Cruz Biotechnology), Tyr 705-phosphorylated STAT3 (STAT3-P, 1:10,000, sc-7993-R, Santa Cruz Biotechnology), $\beta 1$-integrin $(1: 1,000$, sc-8978, Santa Cruz Biotechnology), and FAK (1:1000, sc-557, Santa Cruz Biotechnology). Following 3 further washes in TBSTBSA, membranes were incubated for $1 \mathrm{~h}$ in TBST-BSA with 1:10,000 goat anti-rabbit secondary antibody conjugated to horseradish peroxidase (Sigma-Aldrich Co Ltd., Gillingham, UK), except for STAT5-P, which was incubated in TBST-BSA with 1:15,000 sheep antimouse secondary antibody conjugated to horseradish peroxidase (Silenus Labs Pty Ltd., Boronia, Australia). Finally, membranes were washed in TBST-BSA 3 times followed by 4 washes in TBS. To visualize the immunoreactive bands, membranes were incubated for $1 \mathrm{~min}$ in ECL Western blotting detection reagents (Amersham, GE Healthcare, Chalfont St. Giles, UK) and then exposed to X-Omat AR film (Carestream Health Inc., Rochester, NY) for 2 to 30 min, depending on the protein of interest. Films were scanned using a densitometer (GS 800, BioRad, Auckland, New Zealand) and the densities of immunoreactive bands were determined using Quantity One software (BioRad).

\section{Histological Analysis}

Sections were cut from paraffin-embedded, formaldehyde-fixed mammary tissue samples and then stained with hematoxylin and eosin as described in Singh et al. (2005). One section per mammary tissue sample ( $\mathrm{n}=$ 10 per treatment) was assayed. Sections were viewed at $100 \times$ magnification using a binocular microscope (Olympus Optical Co. Ltd., London, UK). All alveoli of each section were categorized into either the "lactating" phenotype or the "involuting" phenotype using descriptions from Holst et al. (1987) as a guide. Alveoli were considered to have the "lactating" phenotype when cells had a regular cuboidal appearance and the alveolar lumen occupied most of the tissue area with little interalveolar space. Alveoli were considered to have the "involuting" phenotype when cells were irregular and contained several large vacuoles, the lumen appeared collapsed, and the interalveolar space was more obvious. The "lactating" phenotype proportion of alveoli for each section was calculated by dividing the number of "lactating" phenotype alveoli by total number of alveoli counted. Total number of alveoli counted per section was $>250$.

\section{Statistical Analysis}

Differences between $\log _{10}$-transformed relative mRNA abundance, $\log _{10}$-transformed protein densities, and proportion of "lactating" phenotype were analyzed by ANOVA (Minitab 16.2.2, 2010; Minitab Inc., State College, PA) by treatment (MF), with cow as a random effect. $\log _{10}$-transformed relative mRNA abundance was expressed as treatment mean and fold change, which was calculated by back-transformation of the difference between the treatment means $(4 \times-1 \times)$. $\log _{10}$-transformed protein densities was expressed as a ratio of treatment mean $(4 \times: 1 \times) \pm$ standard error of the difference. "Lactating" phenotype proportion was expressed as treatment mean \pm SEM. Differences between means were considered significant at $P<0.05$. Correlations between $\log _{10}$-transformed relative mRNA abundance of milk protein genes, $\log _{10}$-transformed protein densities of STAT5-P, STAT3-P, and $\beta 1$-integrin, and $\log _{10}$-transformed "lactating" phenotype proportion were performed with Minitab.

\section{RESULTS}

\section{Changes in PRL Signaling Pathway in Response to MF}

Relative mRNA and protein levels of PRLR and STAT5 were measured in the 2 treatment groups to determine the effects of MF. The relative mRNA abundance of both the long and short isoforms of $P R L R$ and the protein abundance of the long isoform PRLR were lower in $4 \times$ mammary tissue samples compared with $1 \times$ samples (Table 2 and Figure 1 ). The relative abundance of STAT5A mRNA and STAT5 protein abundance were higher in $4 \times$ mammary tissue samples compared with $1 \times$ samples (Table 2 and Figure 1). Activation of the pathway was evaluated by measuring the phosphorylation of tyrosine 694 within the STAT5 protein. The level of STAT5-P was 40 times higher in $4 \times$ mammary tissue samples compared with $1 \times$ samples (Figure 1). Within all mammary tissue samples, the levels of STAT5-P correlated strongly with the mRNA abundance of CSN1S1 (Figure 2A). Similar correlations were observed with the mRNA abundance of CSN2, LALBA, and $L G B(\mathrm{r}=0.95,0.96$, and 0.91 respectively; data not shown).

\section{Changes in STAT3 Activation and Extracellular Matrix/B1-Integrin Pathway Constituents in Response to MF and Correlation with STAT5 Activation}

To investigate whether cross-talk between pathways plays a role in STAT5 activation, we measured the abundance and activation of STAT3, and the abundance of $\beta 1$-integrin and FAK. The level of STAT3 mRNA was 
Table 2. Relative mRNA abundance for genes of interest in mammary tissue collected from dairy cow udder halves unilaterally milked 4 times a day $(4 \times)$ or once a day $(1 \times)$ in early lactation

\begin{tabular}{lcccc}
\hline & \multicolumn{2}{c}{ Milking frequency $^{2}$} & & \\
\cline { 2 - 3 } Target $^{1}$ & $4 \times$ & & $\begin{array}{c}\text { Fold } \\
\text { change }^{3}\end{array}$ & P-value $^{4}$ \\
\hline PRLR (short) & -1.487 & -1.391 & 0.79 & 0.002 \\
PRLR (long) & -0.876 & -0.681 & 0.69 & 0.001 \\
STAT5A & -2.137 & -2.263 & 1.33 & 0.05 \\
STAT3 & -1.598 & -1.351 & 0.57 & 0.001 \\
ITGB1 & -1.204 & -1.142 & 0.87 & NS \\
FAK & -1.901 & -1.842 & 0.87 & NS \\
\hline
\end{tabular}

${ }^{1} P R L R$ (short) $=$ prolactin receptor short isoform; PRLR (long) = prolactin receptor long isoform; $S T A T 5 A=$ signal transducer and activator of transcription $5 \mathrm{~A} ; S T A T 3=$ signal transducer and activator of transcription 3; $I T G B 1=\beta 1$-integrin; $F A K=$ focal adhesion kinase.

${ }^{2}$ Mean $\log _{10}$-transformed relative mRNA abundance derived from take-off value as described in the Methods.

${ }^{3}$ Fold change in abundance derived by back-transformation of the difference of the transformed values between treatments $(4 \times-1 \times)$.

${ }^{4}$ Probability of the difference between treatments occurring by chance. Difference was considered not significant at $P>0.05$

lower in $4 \times$ mammary tissue samples compared with $1 \times$ samples (Table 2). At the protein level, STAT3 was not significantly different between the 2 treatments (Figure 1), whereas levels of phosphorylated STAT3 were 5 times lower in the $4 \times$ mammary tissue samples compared with $1 \times$ samples (Figure 1 ). The levels of $\beta 1$-integrin protein was 5 times higher in $4 \times$ mammary tissue samples compared with $1 \times$ samples (Figure 1), whereas the relative abundance of $\beta 1$-integrin and FAK mRNA (Table 2) and the levels of FAK protein were not significantly different between the 2 treatments (Figure 1). Within all mammary tissue samples, the levels of STAT5-P protein correlated highly with the levels of $\beta 1$-integrin protein (Figure 2B), whereas a negative correlation was detected between the levels of STAT5-P and STAT3-P proteins (Figure 2C).

\section{Effects of MF on Mammary Alveoli Phenotype and Correlation with STAT5 Activation and $\beta 1$-Integrin}

Generally, the mammary tissue from both treatment groups was heterogeneous, with areas of alveoli displaying either the "lactating" phenotype (a representative image shown in Figure 3A) or the "involuting" phenotype (a representative image shown in Figure 3B). Areas of the mammary tissue sections consisting of predominantly "lactating" phenotype typically had larger ordered alveoli with clearly defined lumen and less interalveolar space. The alveoli consisted of cuboidal MEC that were regularly spaced (Figure 3A). In contrast, alveoli typical in areas of the mammary tissue sections consisting predominantly of the "involuting" phenotype were smaller, irregularly shaped, with collapsed lumen. These alveoli consisted of disordered MEC, with nu- merous cells containing unstained cytoplasmic vacuoles (Figure 3B). A 4-fold-higher proportion of "lactating" phenotype alveoli was detected in the $4 \times$ mammary tissue samples compared with $1 \times$ samples (Figure $3 \mathrm{C}$ ). The proportion of "lactating" phenotype alveoli correlated highly with the levels STAT5-P protein (Figure 2D) and 31-integrin protein (Figure 2E), and correlated negatively with the levels of STAT3-P protein (Figure $2 \mathrm{C})$.

\section{DISCUSSION}

Previous studies have demonstrated that the effects of MF on milk production are controlled locally within the mammary gland (Hillerton et al., 1990; Stelwagen and Knight, 1997). In accordance with this, the increase of STAT 5 activation in the $4 \times$ mammary tissue reported in the present study is likely due to local intramammary signals. Furthermore, the activation of STAT5 is highly correlated with major milk protein gene mRNA abundance, confirming the importance of this transcription activator in the control of milk synthesis in bovine mammary glands. In MEC, activation of STAT5 is mediated by PRL, which signals through PRLR (Hynes et al., 1997). Previous studies in mid-lactation dairy cows have demonstrated that the mRNA abundance of PRLR increases following increased MF (Bernier-Dodier et al., 2010). In contrast, we report a decrease of both $P R L R$ mRNA and protein in the $4 \times$ tissue samples compared with $1 \times$ samples. The discrepancy between reports remains unclear, but it may be due to the differences in the parameters of the experiments; that is, stage of lactation, duration of treatment, and time of sample collection in relation to previous milking. Because of the lack of association 

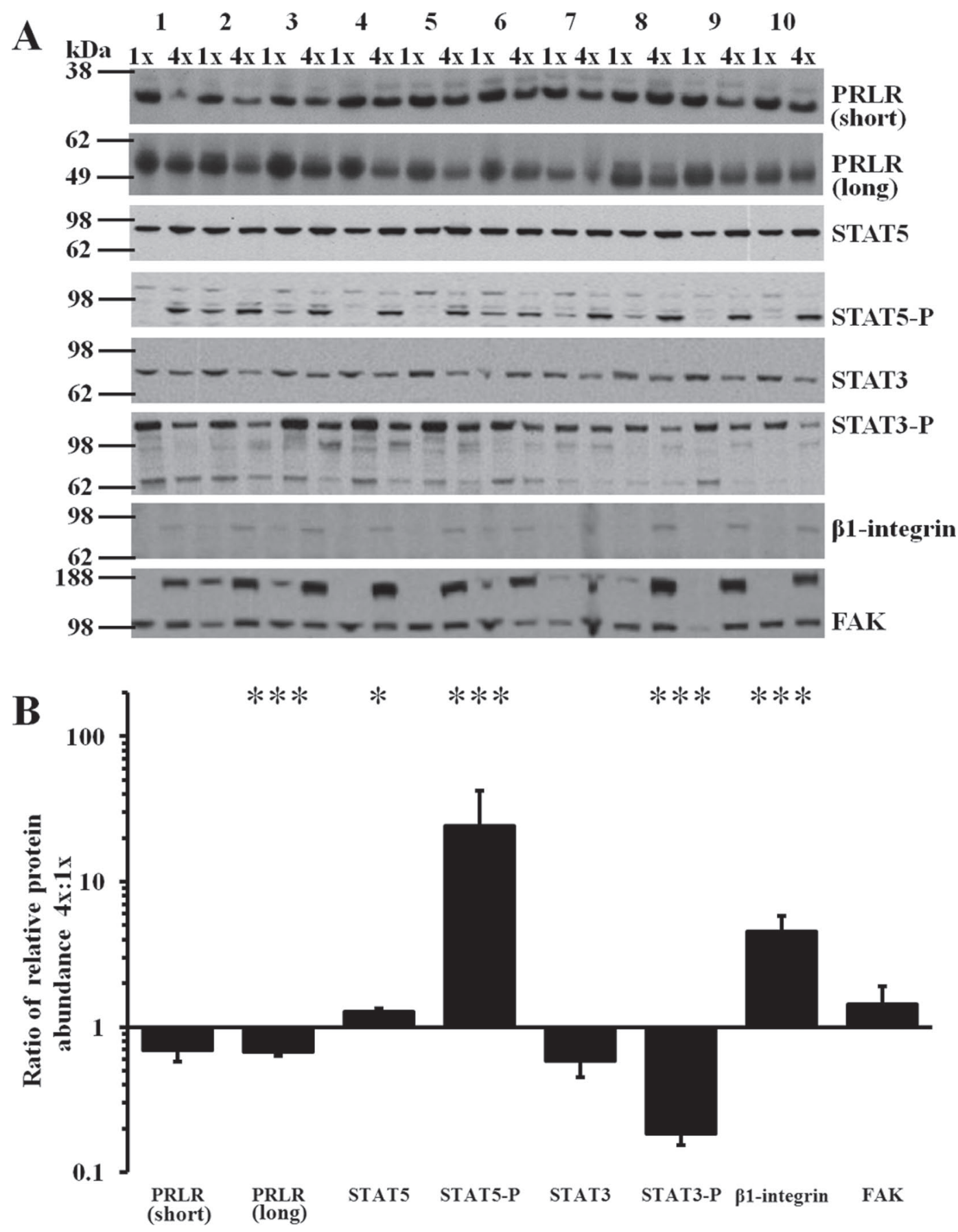

Figure 1. Western blot analysis of key proteins in the prolactin and integrin signaling pathways in mammary tissue extracted from udder halves of dairy cows that had been unilaterally milked either 4 times a day $(4 \times)$ or once a day $(1 \times)$ for $14 \mathrm{~d}$ in early lactation. (A) Independent Western blots for prolactin receptor (PRLR) short and long isoforms, signal transducer and activator of transcription 5 A/B (STAT5), phosphorylated STAT5A/B (STAT5-P), STAT3, phosphorylated STAT3 (STAT3-P), $\beta 1$-integrin, and focal adhesion kinase (FAK) in total protein samples extracted from both the $4 \times$ and $1 \times$ milked udder halves of 10 dairy cows. (B) Difference of the mean protein levels as determined by densitometry of PRLR (short), PRLR (long), STAT5, STAT5-P, STAT3, STAT3-P, $\beta 1$-integrin, and FAK, expressed as the ratio of abundance in $4 \times$ compared with the $1 \times\left( \pm\right.$ standard error of the difference); ${ }^{*} P \leq 0.05,{ }^{* * *} P \leq 0.001$.

between levels of STAT5 activation and PRLR protein, our results suggest that the abundance of PRLR is not a limiting factor in the ability of MEC to respond to PRL stimulus.
In mice, the $\beta 1$-integrin cell surface receptor influences the PRL sensitivity of MEC (Naylor et al., 2005; Akhtar and Streuli, 2006). In agreement with this, the elevated levels of $\beta 1$-integrin protein in the $4 \times$ tissue 

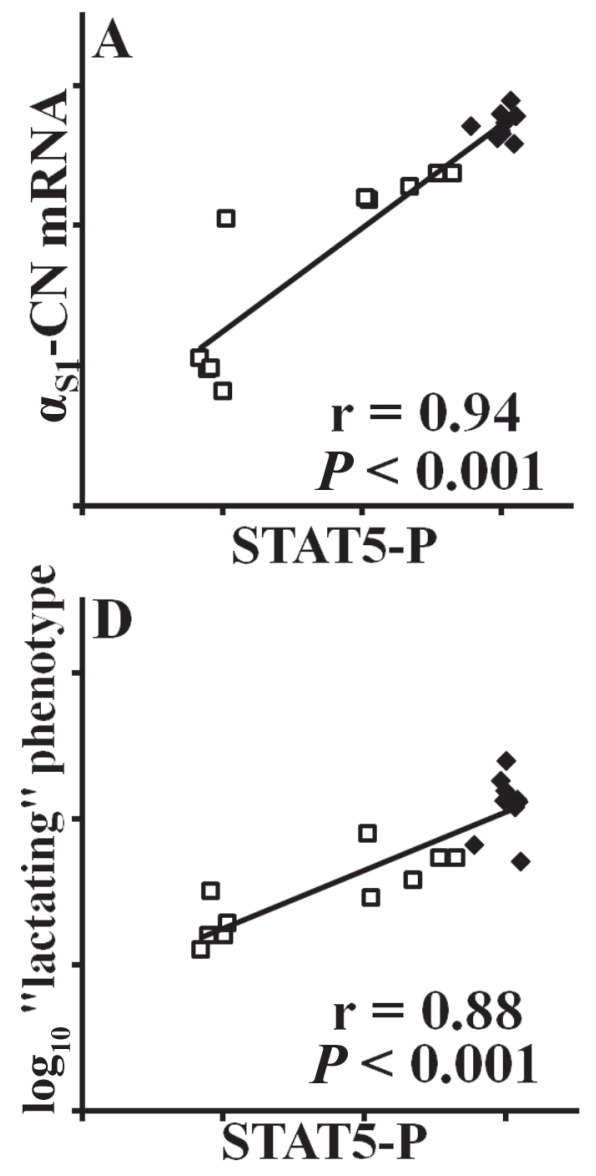
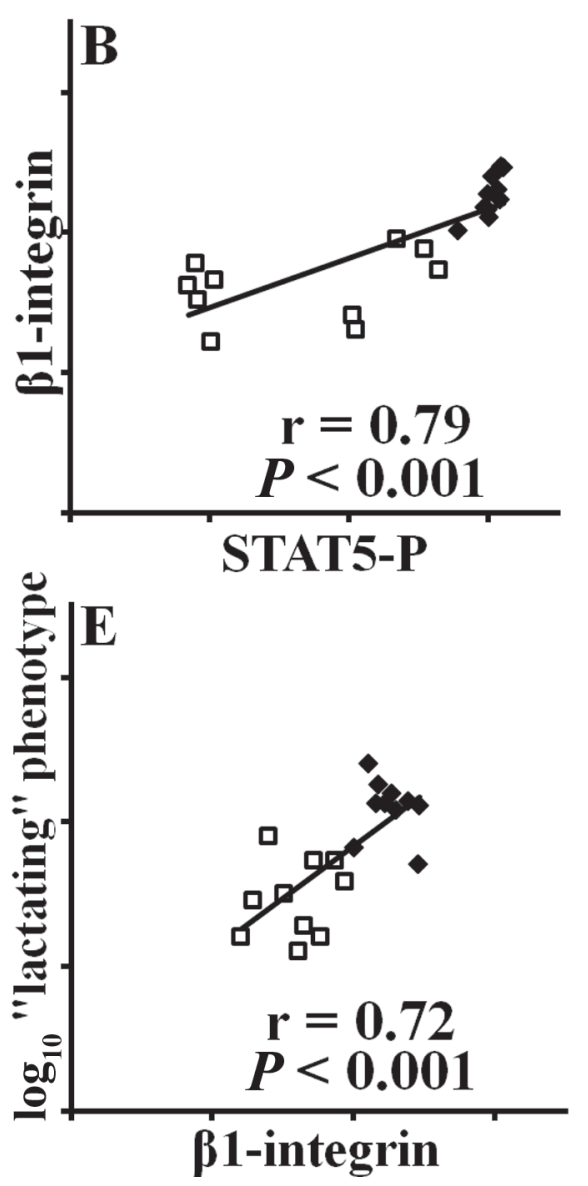

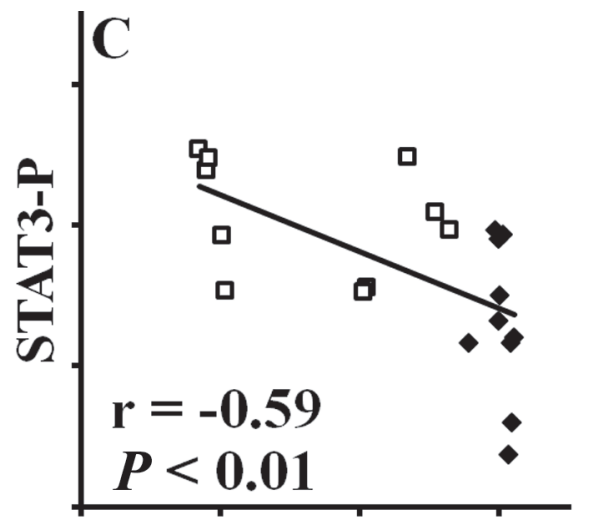

STAT5-P

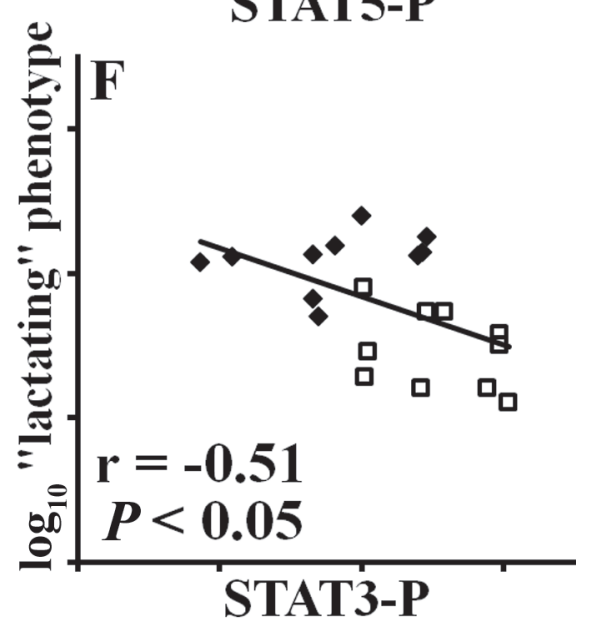

Figure 2. Correlations between phosphorylated signal transducer and activator of transcription 5 A/B (STAT5-P) protein abundance and CSN1S1 $\left(\alpha_{S_{1}}-\mathrm{CN}\right)$ mRNA abundance $(\mathrm{A})$, STAT5-P protein abundance and $\beta 1$-integrin protein abundance (B), STAT5-P protein abundance and phosphorylated STAT3 (STAT3-P) protein abundance (C), STAT5-P protein abundance and proportion of alveoli exhibiting the "lactating" phenotype (D), $\beta 1$-integrin protein abundance and proportion of alveoli exhibiting the "lactating" phenotype (E), and STAT3-P protein abundance and proportion of alveoli exhibiting the "lactating" phenotype (F) in mammary tissue extracted from udder halves of dairy cows subjected to differential milking for either 4 times a day $(4 \times, \diamond)$ or once a day $(1 \times, \square)$ for $14 \mathrm{~d}$ in early lactation. All data are $\log _{10}$-transformed with regression fits and Pearson correlation ( $\mathrm{r}$ ) for all data points $(4 \times$ and $1 \times$ combined).

samples and correlation with STAT5 activation suggest that modulation of $\beta 1$-integrin levels might also mediate the responsiveness of the MEC to PRL in bovine mammary glands. One possible mechanism for a causative link between these 2 signaling proteins is via Ras-related C3 botulinum toxin substrate 1 (Rac1; Akhtar and Streuli, 2006). In the present study, we were unable to detect Rac1, thus its role linking STAT5 and integrin signaling in the bovine mammary gland remains unverified. The regulation of $\beta 1$-integrin must occur posttranscriptionally because abundance of $\beta 1$ integrin mRNA was unaffected by MF. It is unknown how protein levels of $\beta 1$-integrin are maintained in MEC or how MF modulates their abundance and this question requires further study.

During involution, the activation of STAT5 diminishes and, at the same time, activation of STAT3 in- creases (Kritikou et al., 2003; Singh et al., 2009). It is thought that STAT3 can act as an antagonist to STAT5, preventing further activation when the gland shuts down milk production in response to infection or cessation of milking (Granillo et al., 2007). A negative relationship between STAT5 and STAT3 activation was also demonstrated in the current study. Whether activation of STAT3 in the $1 \times$ tissue samples inhibited STAT5 activation or vice versa in the $4 \times$ tissue samples is unclear. Activation of STAT3 occurs as part of the immune response in mammary glands and increases during mastitis (M. Prewitz, formerly of AgResearch, Hamilton, New Zealand, and K. Singh, unpublished data) and involution (Singh et al., 2009). Therefore, the increase in STAT3 activation detected within the $1 \times$ tissue samples may indicate that an immune response has been initiated in response to decreased MF. In ac- 

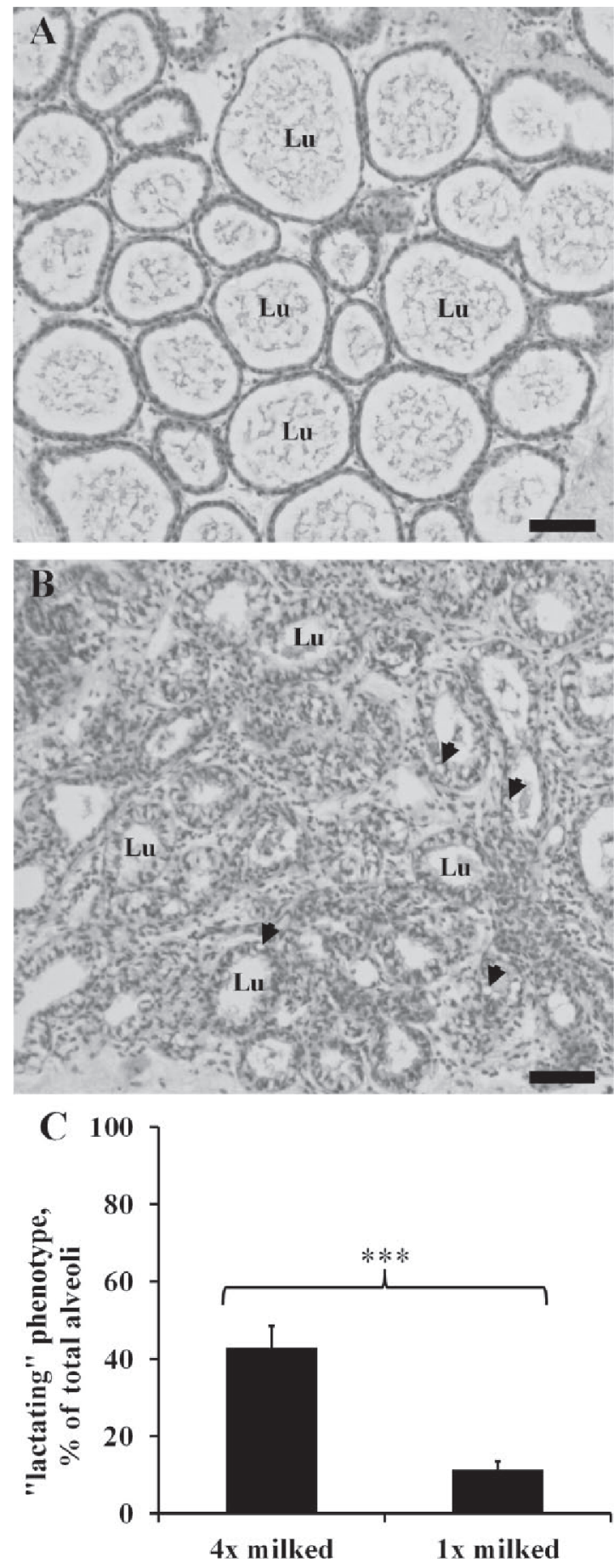

Figure 3. Phenotypic analysis of mammary tissue extracted from udder halves unilaterally milked either 4 times a day $(4 \times)$ or once a day $(1 \times)$ for $14 \mathrm{~d}$ in early lactation. (A) Representative image of mammary parenchyma from the $4 \times$-milked udder half of cow 10, exhibiting the "lactating" phenotype. (B) Representative image of mammary parenchyma from the $1 \times$-milked udder half of cow 10 , exhibiting the "involuting" phenotype. Sections were stained with hematoxylin and eosin. Several alveolar lumen $(\mathrm{Lu})$ are evident in both images; black arrows indicate several of the cytoplasmic vacuoles within the mammary epithelial cells in alveoli exhibiting the "involuting" phenotype. (C) Mean percentage of alveoli exhibiting the "lactating" phenotype in $4 \times$ and $1 \times$ mammary tissue sections $( \pm \mathrm{SEM}) ;{ }^{* * *} P \leq 0.001$. cordance with this, an increase in lactoferrin mRNA abundance in these $1 \times$ milked samples has previously been reported (Murney et al., 2015); lactoferrin is also upregulated during mastitis (Harmon et al., 1975) and involution (Schanbacher et al., 1993). It is possible, therefore, that STAT5 and STAT3 activation never coincide in the same MEC and occur independently of each other, being activated only in different MEC states; that is, actively secreting MEC for STAT5 and immune response-activated MEC for STAT3.

Previous studies have shown that normally lactating bovine mammary glands are heterogeneous (Molenaar et al., 1992). The secretory MEC can be divided into 2 distinct sub-populations, either actively secreting MEC that are expressing genes associated with milk synthesis, or quiescent MEC, which instead are expressing immune-related genes, such as lactoferrin (Molenaar et al., 1992). The results presented in this study demonstrate that the proportions of the 2 sub-populations of MEC can be modulated by MF. These results suggest that MEC switch between active secretory and quiescence, increasing or decreasing the proportions in response to MF stimuli, which has been postulated as a possible mode of action of MF (Vetharaniam et al., 2003). Furthermore, the results demonstrate a link between the overall activity of the mammary tissue; that is, milk protein gene expression and STAT5 activation, and the proportion of phenotypically "lactating" alveoli, suggesting that this switching of quiescent MEC to actively secreting MEC is indeed the mechanism that controls the increase in milk synthesis in bovine mammary glands, rather than a uniform increase in activity across all MEC. How the switching of MEC from quiescent to actively secretory is controlled is not fully understood, but the correlation between $\beta 1$-integrin and the secretory activity of the mammary tissues may indicate a role for extracellular matrix signaling through $\beta 1$-integrin and the switching of MEC from quiescent to actively secretory.

\section{CONCLUSIONS}

The data presented here suggest that $\beta 1$-integrin protein abundance is closely linked to STAT5 activation in bovine mammary glands subjected to UMF. We propose that $\beta 1$-integrin permits sustained STAT5 activation, and abundance of $\beta 1$-integrin protein is controlled as a mechanism to alter the MEC sensitivity to PRL rather than constituents of the PRL signaling pathway. It appears that secretory activity is controlled at the alveolar level and that the proportion of phenotypically "lactating" alveoli is increased in the $4 \times$ mammary tissue samples compared with $1 \times$ mammary tissue samples. 


\section{ACKNOWLEDGMENTS}

The authors acknowledge Bruno Botaro, Eric Brijs, Chris Couldrey, Brad Hine, Kara Swanson, and the farm staff at the Tokanui Research Farm (AgResearch, Hamilton, New Zealand) for assistance with the animal trial and sample collections. We also acknowledge Harold Henderson (AgResearch) for his advice in statistical analysis. This research was funded by a Ministry of Business, Innovation \& Employment (New Zealand) research grant (no. C10X0702).

\section{REFERENCES}

Akers, R. M., D. E. Bauman, A. V. Capuco, G. T. Goodman, and H. A. Tucker. 1981. Prolactin regulation of milk secretion and biochemical differentiation of mammary epithelial cells in periparturient cows. Endocrinology 109:23-30.

Akhtar, N., and C. H. Streuli. 2006. Rac1 links integrin-mediated adhesion to the control of lactational differentiation in mammary epithelia. J. Cell Biol. 173:781-793.

Bernier-Dodier, P., L. Delbecchi, G. F. Wagner, B. G. Talbot, and P. Lacasse. 2010. Effect of milking frequency on lactation persistency and mammary gland remodeling in mid-lactation cows. J. Dairy Sci. 93:555-564.

Boutinaud, M., L. Galio, V. Lollivier, L. Finot, S. Wiart, D. Esquerré, and E. Devinoy. 2013. Unilateral once daily milking locally induces differential gene expression in both mammary tissue and milk epithelial cells revealing mammary remodeling. Physiol. Genomics 45:973-985.

Bradford, M. M. 1976. A rapid and sensitive method for the quantitation of microgram quantities of protein utilizing the principle of protein dye binding. Anal. Biochem. 72:248-254.

Capuco, A. V., D. L. Wood, R. Baldwin, K. McLeod, and M. J. Paape. 2001. Mammary cell number, proliferation, and apoptosis during a bovine lactation: Relation to milk production and effect of bST. J. Dairy Sci. 84:2177-2187.

Carruthers, V. R., S. R. Davis, A. M. Bryant, H. V. Henderson, C. A. Morris, and P. J. A. Copeman. 1993. Response of Jersey and Friesian cows to once a day milking and prediction of response based on udder characteristics and milk composition. J. Dairy Res. 60:1-11.

Clarkson, R. W. E., M. P. Boland, E. A. Kritikou, J. M. Lee, T. C. Freeman, P. G. Tiffen, and C. J. Watson. 2006. The genes induced by signal transducer and activators of transcription (STAT) 3 and STAT5 in mammary epithelial cells define the roles of these STATs in mammary development. Mol. Endocrinol. 20:675-685.

Erdman, R. A., and M. Varner. 1995. Fixed yield responses to increased milking frequency. J. Dairy Sci. 78:1199-1203.

Farr, V. C., K. Stelwagen, L. R. Cate, A. J. Molenaar, T. B. McFadden, and S. R. Davis. 1996. An improved method for the routine biopsy of bovine mammary tissue. J. Dairy Sci. 79:543-549.

Flint, D. J., and C. H. Knight. 1997. Interactions of prolactin and growth hormone $(\mathrm{GH})$ in the regulation of mammary gland function and epithelial cell survival. J. Mammary Gland Biol. Neoplasia 2:41-48.

Granillo, A. R., J. C. Boffi, L. Baranao, E. Kordon, A. Pecci, and A. Guberman. 2007. STAT5 transcriptional activity is impaired by LIF in a mammary epithelial cell line. Biochem. Biophys. Res. Commun. 356:727-732.

Harmon, R. J., F. L. Schanbacher, L. C. Ferguson, and K. L. Smith. 1975. Concentration of lactoferrin in milk of normal lactating cows and changes occurring during mastitis. Am. J. Vet. Res. 36:1001-1007.

Hillerton, J. E., C. H. Knight, A. Turvey, S. D. Wheatley, and C. J. Wilde. 1990. Milk yield and mammary function in dairy cows milked four times daily. J. Dairy Res. 57:285-294.
Holst, B. D., W. L. Hurley, and D. R. Nelson. 1987. Involution of the bovine mammary gland: histological and ultrastructural changes. J. Dairy Sci. 70:935-944.

Hynes, N. E., N. Cella, and M. Wartmann. 1997. Prolactin mediated intracellular signaling in mammary epithelial cells. J. Mammary Gland Biol. Neoplasia 2:19-27.

Ingalls, W. G., E. M. Convey, and H. D. Hafs. 1973. Bovine serum LH, $\mathrm{GH}$, and prolactin during late pregnancy, parturition and early lactation. Proc. Soc. Exp. Biol. Med. 143:161-164.

Knight, C. H., D. T. Calvert, and D. J. Flint. 1986. Inhibitory effects of bromocriptine on mammary development and function in lactating mice. J. Endocrinol. 110:263-270.

Kritikou, E. A., A. Sharkey, K. Abell, P. J. Came, E. Anderson, R. W. E. Clarkson, and C. J. Watson. 2003. A dual, non-redundant, role for LIF as a regulator of development and STAT3-mediated cell death in mammary gland. Development 130:3459-3468.

Lacasse, P., V. Lollivier, R. M. Bruckmaier, Y. R. Boisclair, G. F. Wagner, and M. Boutinaud. 2011. Effect of the prolactin-release inhibitor quinagolide on lactating dairy cows. J. Dairy Sci. 94:1302-1309.

McMahon, C. D., V. C. Farr, K. Singh, T. T. Wheeler, and S. R. Davis. 2004. Decreased expression of $\beta 1$-integrin and focal adhesion kinase in epithelial cells may initiate involution of mammary glands. J. Cell. Physiol. 200:318-325.

Molenaar, A. J., S. R. Davis, and R. J. Wilkins. 1992. Expression of alpha-lactalbumin, alpha-S1-casein, and lactoferrin genes is heterogeneous in sheep and cattle mammary tissue. J. Histochem. Cytochem. 40:611-618.

Murney, R., K. Stelwagen, T. T. Wheeler, J. K. Margerison, and K. Singh. 2015. The effects of milking frequency in early lactation on milk yield, mammary cell turnover and secretory activity in grazing dairy cows. J. Dairy Sci. 98:305-311.

Naylor, M. J., N. Li, J. Cheung, E. T. Lowe, E. Lambert, R. Marlow, P. Wang, F. Schatzmann, T. Wintermantel, G. Schuetz, A. R Clarke, U. Mueller, N. E. Hynes, and C. H. Streuli. 2005. Ablation of beta1 integrin in mammary epithelium reveals a key role for integrin in glandular morphogenesis and differentiation. J. Cell Biol. 171:717-728.

Rémond, B., J. B. Coulon, M. Nicloux, and D. Levieux. 1999. Effect of temporary once-daily milking in early lactation on milk production and nutritional status of dairy cows. Ann. Zootech. (Paris) 48:341-352.

Roskelley, C. D., A. Srebrow, and M. J. Bissell. 1995. A hierarchy of ECM-mediated signalling regulates tissue-specific gene expression. Curr. Opin. Cell Biol. 7:736-747.

Schanbacher, F. L., R. E. Goodman, and R. S. Talhouk. 1993. Bovine mammary lactoferrin: Implications from messenger ribonucleic acid (mRNA) sequence and regulation contrary to other milk proteins. J. Dairy Sci. 76:3812-3831.

Shaar, C. J., and J. A. Clemens. 1972. Inhibition of lactation and prolactin secretion in rats by ergot alkaloids. Endocrinology 90:285-288.

Singh, K., S. R. Davis, J. M. Dobson, A. J. Molenaar, T. T. Wheeler, C. G. Prosser, V. C. Farr, K. Oden, K. M. Swanson, C. V. C. Phyn, D. L. Hyndman, T. Wilson, H. V. Henderson, and K. Stelwagen. 2008. cDNA microarray analysis reveals that antioxidant and immune genes are upregulated during involution of the bovine mammary gland. J. Dairy Sci. 91:2236-2246.

Singh, K., J. Dobson, C. V. C. Phyn, S. R. Davis, V. C. Farr, A. J. Molenaar, and K. Stelwagen. 2005. Milk accumulation decreases expression of genes involved in cell-extracellular matrix communication and is associated with induction of apoptosis in the bovine mammary gland. Livest. Prod. Sci. 98:67-78.

Singh, K., I. Vetharaniam, M. Prewitz, J. M. Dobson, and K. Stelwagen. 2009. Understanding the interaction of prolactin and leukaemia inhibitory factor signalling during the switch from lactation to involution: Brief communication. Proc. N.Z. Soc. Anim. Prod. 69:65-67.

Smith, C. S., D. K. Berg, M. Berg, and P. L. Pfeffer. 2010. Nuclear transfer-specific defects are not apparent during the second week of embryogenesis in cattle. Cell. Reprogram. 12:699-707. 
Smith, V. G., T. W. Beck, E. M. Convey, and H. A. Tucker. 1974. Bovine serum prolactin, growth hormone, cortisol and milk yield after ergocryptine. Neuroendocrinology 15:172-181.

Stelwagen, K. 2001. Effect of milking frequency on mammary functioning and shape of the lactation curve. J. Dairy Sci. 84:E204-E211.

Stelwagen, K., and C. H. Knight. 1997. Effect of unilateral once or twice daily milking of cows on milk yield and udder characteristics in early and late lactation. J. Dairy Res. 64:487-494.

Sympson, C. J., R. S. Talhouk, C. M. Alexander, J. R. Chin, S. M. Clift, M. J. Bissell, and Z. Werb. 1994. Targeted expression of stromelysin-1 in mammary gland provides evidence for a role of proteinases in branching morphogenesis and the requirement for an intact basement membrane for tissue-specific gene expression. J. Cell Biol. 125:681-693.

Untergasser, A., I. Cutcutache, T. Koressaar, J. Ye, B. C. Faircloth, M. Remm, and S. G. Rozen. 2012. Primer3-New capabilities and interfaces. Nucleic Acids Res. 40:e115.
Vetharaniam, I., S. R. Davis, T. K. Soboleva, P. R. Shorten, and G. C. Wake. 2003. Modeling the interaction of milking frequency and nutrition on mammary gland growth and lactation. J. Dairy Sci. 86:1987-1996.

Wall, E. H., and T. B. McFadden. 2007. The milk yield response to frequent milking in early lactation of dairy cows is locally regulated. J. Dairy Sci. 90:716-720.

Wall, E. H., and T. B. McFadden. 2010. The effects of milk removal or four-times-daily milking on mammary expression of genes involved in the insulin-like growth factor-I axis. J. Dairy Sci. 93:4062-4070.

Wheeler, T. T., M. K. Broadhurst, H. B. Sadowski, V. C. Farr, and C. G. Prosser. 2001. Stat5 phosphorylation status and DNA-binding activity in the bovine and murine mammary glands. Mol. Cell. Endocrinol. 176:39-48. 